\title{
COMENTARIO
}

\section{¿Más allá del capital y del Estado? Cuatro pro(a)puestas por la vida y un comentario...}

\author{
Mónica Gallegos Ramírez
}

La modernidad viene prometiendo realizar los más grandes sueños de la humanidad desde hace cinco siglos;

en nombre de estas aspiraciones nos conduce al actual callejón sin salida que padece la humanidad: la múltiple crisis civilizatoria que agudiza la muerte del planeta y de toda la vida. Se trata de una racionalidad irracional que sólo sabe destruir para producir; por eso se trata de una racionalidad que es imposible de superar si es que no se ha salido, lógica y existencialmente, de ella.

Rafael Bautista.

$\mathrm{L}$ os movimientos sociales, los pueblos, las llamadas sociedades en movimiento (Zibechi, 2007), la gente sencilla y común (Subcomandante insurgente Marcos-CCRI-CGEZLN, 2005) han expresado con más fuerza en los últimos años y de formas diversas una necesidad histórica que apuesta por la vida, por una forma de vida más humana y más digna (Bautista, 2011). La emergencia notoria de las llamadas luchas socioambientales - Tischler y Navarro-y las luchas de emancipación -Gutiérrez- son parte del mismo proceso. Considero que al mismo tiempo vamos entendiendo que el camino principal para preservar la vida es la creación de vías radicalmente distintas a las que impone la llamada modernidad capitalista, que ha colonizado y sometido al mundo entero a la lógica de la ganancia y de la expansión permanente y continuada a cualquier costo, humano y de la naturaleza, del proceso de acumulación de riqueza. Entonces parece pertinente preguntarnos: ¿qué supone la descolonización de la vida toda, del hacer cotidiano, del pensamiento? Esta pregunta abre otras: ¿a quiénes y para qué importa tal descolonización? ¿De qué manera se vincula este proceso con la necesidad de ir más allá del capital y el Estado?

Beyond the Capital and the State? Four Proposals (Bets) for Life and a Comment

(Trying to Collect Potencial and Think Decolonization)

Mónica Gallegos Ramírez: Centro Universitario de Ciencias Sociales y Humanidades, Universidad de Guadalajara,

Guadalajara, Jalisco, México

monikg4@yahoo.com.mx

Desacatos, núm. 37, septiembre-diciembre 2011, pp. 81-90 
Sabemos lo que supone el funcionamiento de la modernidad capitalista: la opresión sobre las mentes y los cuerpos, la anulación de todas las potencialidades individuales y sociales, la alineación a un tiempo y un espacio planos en los que sólo prima la ganancia y el ritmo que marca el fetiche principal -el dinero- a golpe de mercantilización de la vida toda; la destrucción paciente y continuada de la vida natural y humana. La imposición cotidiana de su lógica de funcionamiento se presenta por todos los medios como la única, la mejor, y clausura las posibilidades creativas e imaginativas de la humanidad entera por la vía de la certeza aniquilante de la repetición. Frente a todo ello, la gente sencilla y humilde, la gente común, se resiste, se indisciplina, se rebela y dice ¡no! (Holloway, 2002). En el caso reciente de la insubordinación popular en los países del norte de África, Sadri Khiari (2011) expresa con crudeza que existen:

resistencias moleculares que se condensan y explo- tan a la vista de todos a su debido tiempo. A la opacidad del poder despótico se corresponde la opacidad de las resistencias; las vergonzosas formas de lealtad y clientelización caminan de la mano de la construcción de solidaridades populares; las tecnologías de control y de disciplina se acompañan de dispositivos de esquiva, de camuflaje, de evasión y de transgresión que perturban el orden establecido.

A pesar de todas las evidencias, la modernidad capitalista insiste en presentarse como fin último y trata de convencernos, por todos los medios, de que no hay otra alternativa más que ella misma. $\mathrm{Al}$ respecto, Franz Hinkelammert (1991) se pregunta: ¿qué tan buena puede ser una alternativa en la que no hay ninguna alternativa posible, es decir, que se presenta sin alternativas? Pero ¿en realidad no hay alternativas? Falso. Los trabajos que comentaremos nos muestran varias. Trataré de ir hilvanando algunas de las ideas expuestas en los artículos contenidos en esta sección de Desacatos, precisamente a la manera en la que quienes aquí escriben nos proponen ir más allá del capital y el Estado.
Comienzo señalando que para Raquel Gutiérrez Aguilar preguntarse sobre la emancipación social a partir de la experiencia boliviana supone explorar la tensión entre las posibilidades, formas, desafíos y dificultades de la gigantesca capacidad social autónoma y su intervención directa en los asuntos públicos y los llamados gobiernos progresistas. Las formas aprendidas y hegemónicas de hacer política se ponen en juego, se discuten no sólo las implicaciones de ejercer el monopolio del mando y la decisión pública, sino el contenido de la noción misma de lo político, del o los sujetos de la emancipación social, de sus formas de hacer, además de la comprensión que podría denominarse "tradicional" del poder frente a la formulación - dice Gutiérrez - de otra acepción del poder "como capacidad - individual y colectiva - de producir, generar y regenerar la vida en sus múltiples dimensiones construyendo y afianzando modalidades autónomas de autorregulación".

El problema hacia el que apunta Raquel Gutiérrez Aguilar no sólo es complicado, sino complejo, pues a pesar de que en los ejemplos que nos expone existía claridad en la perspectiva femenina popular-comunitaria aymara de cómo sería la relación con "el encargado del gobierno", no hubo manera de garantizar que éste apoyara lo que todo el cuerpo social iba decidiendo y que, en efecto, cumpliera con lo que le mandaba. ¿Cómo había que hacer para que el que mandaba, mandara obedeciendo? No obstante, en la experiencia de la "tumultuosa movilización social” boliviana se abrieron algunos espacios para discutir abiertamente cuestiones importantes relacionadas con la necesidad de "desprivatizar" parte de la riqueza común y con la posibilidad de su reapropiación social a través del usufructo y la gestión. Este aspecto resulta decisivo si lo que queremos es transformar la naturaleza de las relaciones sociales, esto es, si pretendemos ir más allá del capital y el Estado. Raquel Gutiérrez Aguilar señala también los límites de esa experiencia y la considera una especie de "reformismo desde abajo" porque "no está claramente planteada la cuestión de la necesaria inversión de la titularidad 


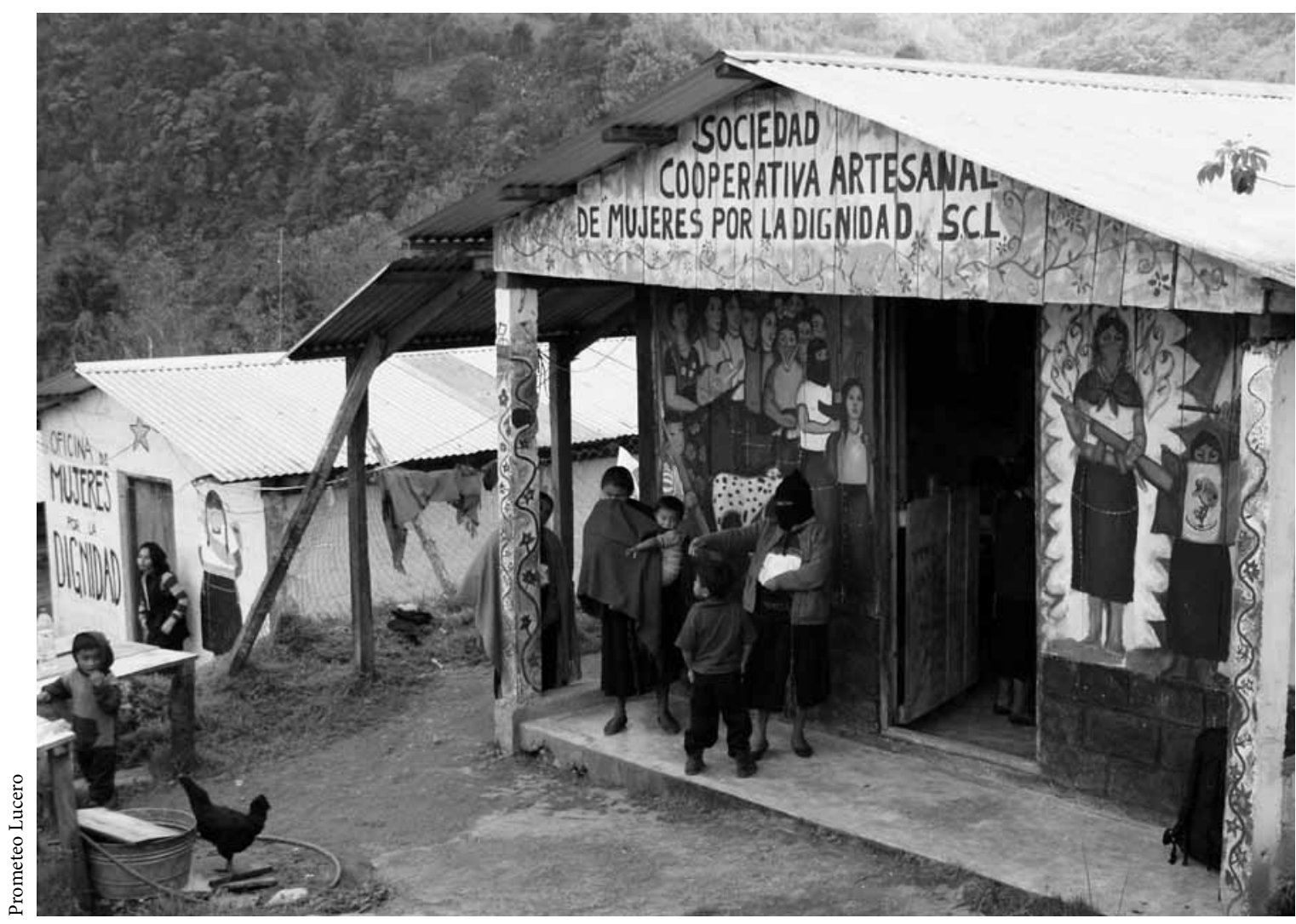

Bases de apoyo en Oventik, Chiapas, diciembre de 2008 a enero de 2009.

de la decisión política, esto es, de las precisiones necesarias para dar vida al 'mandar obedeciendo"'.

Del anterior planteamiento de la autora se puede derivar una afirmación que invita al debate: si existiera claridad suficiente y se hicieran todas las precisiones necesarias sería posible "usar" el mismo aparato de Estado para dar vida al principio de "mandar obedeciendo". ¿Supone esto que el aparato estatal está ahí para ser "usado" y que sólo se require invertir la titularidad de la decisión política para garantizar otras formas de hacer política desde la autonomía, y para hacer efectivo el principio de "mandar obedeciendo"? ¿Será simplemente así? Creemos que no es posible una política de y desde la autonomía a partir de los medios heterónomos representados en el mismo aparato de Estado, o incluso en el capital, los cuales implican la existencia de relaciones sociales fetichizadas. El aparato estatal no es "neutro", su forma de estructuración, los lenguajes y mecanismos de separación que utiliza, las técnicas de gestión y ejercicio del poder que le son inherentes, expresan la enajenación del poder, que se opera vertical e impositivamente, en lugar de ser una creación colectiva y ejercerse de manera horizontal y consensuada por todas y todos. Por tanto, se hace indispensable la discusión sobre el principio de representación política y sus implicaciones. ¿Es sólo cuestión de desechar falsos prejuicios? Me parece que no, pero considero pertinente el señalamiento de Gutiérrez Aguilar en el sentido de no establecer a priori criterios exteriores y universales. La construcción de un mundo otro que vaya más allá del capital y el Estado es una cuestión eminentemente práctica. Dice Gutiérrez Aguilar que la emancipación: 
tiene que ver con las propias prácticas emancipativas inscritas en la actividad política concreta [...] que abrieron nuevas perspectivas para producir $y$ pensar tanto la convivencia social [... y su auto-regulación], como las maneras de preservar y cuidar sus capacidades colectivas para asegurar la intervención autónoma y directa en los asuntos públicos.

La autora hace una distinción entre dos niveles o planos del ejercicio de la autonomía - "auto-centrada" y "expansiva" - y problematiza su posible relación con el Estado porque afirma que no se puede exigir una "coherencia abstracta" si no se aborda, desechando el "olvido ingenuo o interesado", la cuestión primordial de cómo garantizar las "condiciones materiales para la autonomía". ¿Si dichas condiciones no están garantizadas, tendremos que recurrir al Estado y sus políticas? Entiendo que para Gutiérrez Aguilar desde la autonomía se camina hacia la auto-emancipación y, desde ahí, hacia:

la disolución y trastocamiento del poder y del capital, desanudando y rasgando los nudos que le dan fuerza, alterando sus reglas, inhibiendo su enloquecida acumulación. [...] Se trata, entonces, tal como dice la sabiduría femenina aymara, de que "entendamos" el tamaño y la fuerza de nuestra propia capacidad y de que no la rindamos ante nadie. [...] La recuperación y creación cotidiana de esas capacidades [de pensar y hacer] para nosotros mismos es, entonces, la medida del debilitamiento y disolución del otro poder.

La cuestión, por supuesto, que no es lineal ni mucho menos, la autora no la plantea así, aunque me parece central el camino hacia el que apunta para ir más allá del capital y el Estado: recuperemos y creemos cada día para nosotros mismos nuestras capacidades de pensar y hacer. Aquí me gustaría relacionar la reflexión general sobre la política autónoma y las luchas de emancipación que desarrolla Gutiérrez Aguilar con algunas propuestas de Hugo Zemelman, por un lado, y de Rafael Miranda Redondo, por el otro.
Gutiérrez Aguilar argumenta que comprender la problemática de la emancipación social no depende de una teoría sino, más bien, de una estrategia teórica que da cuenta de la "producción práctica y reflexiva de personas situadas socialmente, que asumen determinadas intencionalidades políticas". Al respecto, Hugo Zemelman habla a su vez de las implicaciones de estar histórica y políticamente situados, en particular de la potenciación de los sujetos, desde el reconocimiento de la necesidad histórica hasta el rompimiento de los límites en aras de "atender la demanda de cambio que la realidad nos plantea". Sin embargo, en el tiempo de la modernidad capitalista pierde sentido creer en lo diferente, o no llegamos a tener conciencia de la inconformidad que permite abordar "lo que excede de los límites de una situación dada". Ahora bien, en términos de Castoriadis, el planteamiento anterior supone que en la sociedad actual las significaciones imaginarias sociales nos limitan a "la eficacia", al "éxito" y a los "logros materiales", a la reproducción, a la repetición, pero también son ellas las que abren el espacio a la posibilidad de despliegue de la autonomía como proyecto.

Para Hugo Zemelman, situarse históricamente ante las circunstancias exige trascender los límites, abrir las estructuras, romper los parámetros, entender el movimiento constitutivo de la realidad social y comprender sus posibilidades de desenvolvimiento para, así, distanciarse y construir las categorías que nos permitan nombrar lo que miramos en el horizonte. Este autor se pregunta: “QQué es lo que está más allá [que no puede significarse con un nombre claro de identidad], pero que exige ser nombrado? ¿Cómo decir aquello que para que tenga presencia requiere romper con las formas inteligibles, acabadas y aceptadas?".

Me parece que para el autor es indispensable construir un lenguaje que pueda contener posibilidades de despliegue y potenciación, de forma que permita dar cuenta de esos mismos procesos de la realidad sociohistórica. Esta cuestión supone un enorme desafío en un contexto donde el pensamiento parametral y el lenguaje denotativo son los que predominan 
en el espacio de construcción del conocimiento pretendidamente científico, pero es una exigencia fundamental del pensar histórico.

Respecto de los contenidos y potencialidades de las acciones colectivas que documentan las autoras y autores de los trabajos comentados, considero que pueden inscribirse en lo que Zemelman señala que implica el análisis y la comprensión de la necesidad histórica: "una postura más inclusiva - por tanto, más abierta, diríamos nosotros- que el razonamiento circunscrito a las determinaciones". Lo que implica que en ellos esté dimensionada la categoría de la historicidad a través de la ruptura del tiempo lineal y de la visión determinista de la historia, del reconocimiento de la heterogeneidad de los procesos sociales y de la inclusión de niveles de lo real "que obliga a reflexionar desde horizontes". De igual forma, esta perspectiva se relaciona con la posibilidad de pensar críticamente a partir de los marcos epistémicos de sentido, valóricos - que pretenden dar respuesta al ¿para qué? - y utópicos - que responden al ¿desde dónde? - de los que parte el análisis realizado tanto en los trabajos comentados como en el propio mío.

Zemelman también plantea que el desafío de la historicidad o del pensar histórico lleva al extremo opuesto de los paradigmas hegemónicos de la modernidad capitalista occidental, "extraviados" por las "desviaciones objetivizantes de la ciencia" —ese afán desmedido por la objetividad-, y que "el pensar histórico no puede disociarse de la activación de lo real", en tanto despliegue de las potencialidades de sujetos concretos en situaciones concretas - tal como se analizan en los trabajos referidos-. Pero surge la pregunta: ¿qué más puede suponer para Zemelman la activación de lo real? ¿Se trata del despliegue de las potencialidades subjetivas contenidas en lo real y "susceptibles" de ser desplegadas? ${ }_{i} \mathrm{El}$ autor contempla que unos sujetos pueden $a c t i-$ var a otros o tenemos que hablar necesariamente de un proceso de auto-activación? Creo que el propio Zemelman apunta algunas líneas para una posible discusión sobre estas cuestiones cuando precisa que "la relación entre objetividad y mundo se funda en la necesidad de sentido del mismo sujeto, ya que no puede provenir de algo ajeno a éste sino desde su propio movimiento; más aún, de su apetencia por lo nuevo".

Por su parte, Rafael Miranda Redondo también hace una crítica de la supuesta condición determinada de los sujetos migrantes que analiza, pues no se trata de una situación "forzada" en la que se pierde toda voluntad: "en infinidad de casos la decisión de migrar está mediada por un acto condicionado, pero voluntario". Me parece que su reflexión implica una pregunta: ¿cómo se transforma la dimensión imaginaria social y se crean procesos de sentido que nos resitúan frente a las propias instituciones? A pesar de la importancia de la misma, porque considero que apunta hacia la discusión de lo que podría entenderse por proyecto de autonomía al implicar la transformación de la acción social de instituida a instituyente, el autor responde esta interrogante, y desde ella se mueve para "explorar un camino alterno". Así, a partir del análisis de la obra de Castoriadis recupera nociones importantes, tales como obra institucional, alteridad, clínica de la alteridad, proyecto de autonomía, entre otras, y critica todo aquello que lleva a la identificación, a la necesidad de creer, a la clausura de la ruptura, para señalar que:

\begin{abstract}
la determinidad es entonces el salvavidas de la tradición filosófica heredada [...] de unas leyes de la historia escritas de una vez y para siempre, de la estructura y de la función. Por tanto, el imaginario, como instancia creativa que escapa a la lógica de la determinación, abre la posibilidad a la "ruptura de la clausura $[\ldots]$ una ruptura abierta a la alteridad, [que] se proyectaba hacia la consideración de la modernidad conocida como un proceso inacabado y sugería una segunda modernidad posible y plena”.
\end{abstract}

De igual forma, destaco lo que sostiene Miranda Redondo en cuanto a las condiciones indispensables para que la sociedad transforme sus propias instituciones, teniendo en cuenta que siempre están presentes las dos dimensiones "de lo conjuntante 
identificante y de lo propiamente imaginario, de la repetición y de la creación, de la identidad y la alteridad — se es lo que se es, pero también, al mismo tiempo, se es lo por ser-". Sin embargo, la alteridad ha sido ocultada "detrás de la creencia y la repetición", y por tanto "se oculta la emergencia perpetua del ser como creación". De modo que si "la autonomía no es un valor universal y ella no puede enseñarse, ¿ cómo lidiar [...] con dicha escisión del sujeto y con la condición perpetua del imaginario que una vez crea y otra repite?" Para Miranda Redondo no hay respuesta a esta pregunta más que en el campo de la práctica creativa que rompe con el mito de la propia institución "y entonces renace como sujeto autónomo". Creo que hubiera sido interesante encontrar algunos otros elementos que permitieran tener una idea más cabal del testimonio del autor sobre su propia práctica creativa y sobre su proceso de construcción de autonomía como proyecto.

Ahora bien, si damos por sentado que no son excluyentes y que, además, guardan una estrecha rela-

(1)

ción entre sí, ¿qué más decir sobre las condiciones necesarias para la transformación social, para ir más allá del Estado y el capital, y qué implicaciones tiene hacerlo desde los propios movimientos y luchas o desde los espacios de pensamiento y reflexión? Ambas cuestiones son necesarias e importantes y en todos los trabajos comentados se destaca que son las propias prácticas emancipativas las que inspiran el proceso de reflexión teórica que realizan los sujetos involucrados en ellas.

En el trabajo que presentan Sergio Tischler y Mina Lorena Navarro se analiza la memoria como "una manera de resistir que implica en algunas experiencias la negación abierta de las expresiones más agresivas y predatorias del capital". Resulta muy sugerente el planteamiento acerca del desarrollo de "una política de la memoria como dispositivo de resistencia", aunque considero problemática la forma en que Tischler y Navarro identifican o denominan como luchas socioambientales a las luchas de los pueblos contra el despojo de sus tierras y recursos naturales. Luchas que buscan preservar su vida y sus culturas y que conciben al territorio como algo integral del cual ellos mismos forman parte. Por tanto, se trata de resistencias frente a la posibilidad de desaparecer precisamente como comunidades y como pueblos. Esta cuestión abre, desde mi punto de vista, diversas líneas para un futuro debate: por lo pronto, que la preocupación por lo "ambiental" surgió analizándolo como algo "externo" a la sociedad, que tuvo su origen en los años setenta y nació con una fuerte connotación economicista, buscando primero la sostenibilidad y después la sustentabilidad del desarrollo, e incorporando las "externalidades ambientales" como simples costos.

La noción de "medio ambiente" toma mayor fuerza a partir de la instrumentación del Programa de las Naciones Unidas para el Medio Ambiente, en el seno de la Organización de las Naciones Unidas (ONU) y la Organización de las Naciones Unidas para la Educación, la Ciencia y la Cultura (Unesco). Se ha entendido al medio ambiente principalmente como el medio natural que rodea o se constituye en el entorno de la sociedad. Por tanto, me parece que el actual proceso de acumulación, basado en el despojo de tierras y de recursos naturales, está destruyendo también formas de vida, culturas y maneras alternativas de relacionarnos. Me parece, entonces, que el problema no es sólo ambiental, sino también cultural, social, político, económico y, podría decirse, cosmogónico. De acuerdo con lo que sostienen los autores, diversas comunidades y culturas "enmedio del desgarramiento que han producido las relaciones capitalistas, reafirman sus lazos con la naturaleza y defienden la vida. La disputa que estas luchas libran es por la producción y reproducción de la vida".

Para Tischler y Navarro, el papel de la memoria colectiva como eje de la resistencia frente al despojo tiene que ver con la manera en que ésta organiza las subjetividades y "articula las luchas del pasado [...], conciben los bienes comunes, enfrentan y resisten la desposesión material e inmaterial de la vida y generan alternativas al capitalismo". Los autores argumentan que en el proceso mismo de las luchas se va construyendo un conocimiento que se convierte en 
"una suerte de embrionaria concepción alternativa del mundo surgida de la resistencia a la dominación [...] que apunta a rechazar la idea de la dominación como un hecho objetivo sin fisuras".

La importancia de las experiencias de lucha narradas por Tischler y Navarro tiene que ver también con la potenciación de formas de participación autónomas o no estatales, que rechazan las vías formales-institucionales de decisión, e intervienen colectivamente en los asuntos comunes. Abren aquí el espacio para problematizar acerca de la construcción de la teoría revolucionaria y, siguiendo a Benjamin, afirman que "la producción de conocimiento crítico no es algo exclusivo de la ciencia o de la teoría, sino que tiene un campo fundamental en la elaboración en la resistencia de los colectivos populares, y que cuando la teoría es crítica reconoce en ese flujo colectivo su fuente". Los autores plantean que la memoria colectiva es un dispositivo de resistencia, pero también permite ir más allá del capital y el Estado, en tanto "se presenta como un principio esperanza", que supone una relación distinta presente-pasado y presente-futuro, no lineal ni mecánica, sino que implica una ruptura, un tiempo nuevo que potencia, habilita y permite el despliegue de ciertas capacidades colectivas para enfrentar el capital, para resistir, pero, al mismo tiempo, que anida los "gérmenes de la sociedad futura", la cual se logrará "construyendo el mundo que queremos aquí y ahora".

La radicalidad de estas luchas se profundiza, en tanto se trata de preservar la existencia y la vida como comunidades y como pueblos, buscando alternativas anticapitalistas, pues "forman parte de una relación antagónica con el capital”, pero resisten y la niegan. Para Tischler y Navarro, finalmente, la posibilidad de ir más allá del capital y el Estado supone cuestionar profundamente la noción misma de trabajo "atada servilmente a la idea de progreso [...], que rinde culto a la técnica y a la explotación de la naturaleza [...] y su uso instrumental"; implica también romper con toda práctica cosificadora de la naturaleza, pues tierra, aire, agua son parte del sujeto colectivo y de la totalidad del mundo. En este sentido, destacan la manera en que el zapatismo, por medio de sus prácticas autónomas, "ha jugado un papel central, inspirando ideas que buscan nuevas rutas para un cambio radical". Muchos de los planteamientos vertidos en los trabajos que presenta este número de Desacatos son complementarios en la medida en que apuntan y apuntalan prácticas, pensares, sentires, que dibujan caminos, que dan cuenta de experiencias muy valiosas y de potencialidades que están aguardando su despliegue. Como hemos visto, proponen distintas pero consistentes experiencias que expresan formas de hacer, pensar, sentir, que en diversos planos van más allá del Estado y el capital.

Los variados grados de autodeterminación que manifiesta la experiencia boliviana narrada por Raquel Gutiérrez Aguilar respaldan la idea de que es difícil que se revierta la conciencia histórica que ha logrado este pueblo, o su capacidad para ir construyendo el mundo otro que están necesitando. Sin embargo, son innegables los intentos para recapturar dicha conciencia mediante sofisticadas o burdas estrategias gubernamentales y por medio de las dinámicas mercantiles que en diversos ámbitos sigue tratando de imponer, y muchas veces impone, el capital. Los orígenes de un mundo nuevo, distinto, están contenidos en esas expresiones que enfatizan y reivindican a partir de prácticas concretas la capacidad individual y colectiva de decidir el propio rumbo y de construir un camino alternativo. En particular, es sobre la exigencia de apertura para construir lo inédito, para dejarnos sorprender por lo inesperado, que estamos necesitando como alternativa de vida y como urgencia de mundo otro, que Hugo Zemelman refiere las implicaciones obligadas para los procesos de pensamiento y para el lenguaje, si lo que queremos es dejar atrás todo determinismo y abrirnos como sujetos pensantes y actuantes a la posibilidad de nuestro propio despliegue como sujetos, y a la construcción de maneras distintas a las dictadas por el actual sistema de dominación.

Por su parte Rafael Miranda Redondo, al destacar la importancia del pensamiento de Castoriadis y de su incisiva crítica a todo determinismo en aras 
de dejar de reproducir lo instituido, lo institucional, que lleva a la muerte de toda capacidad creativa y autodeterminante, pone sobre la mesa una cuestión que está presente en todos los trabajos de esta sección de Desacatos: los desafíos que supone caminar hacia la construcción de un proyecto de autonomía. Queda claro que la autonomía como proyecto creativo exige constituirnos explícitamente en sujetos instituyentes a partir del profundo cuestionamiento a la institución, a su clausura, cerrazón, repetición, única vía que garantiza su continuidad, y reivindicar nuestra capacidad creativa - por medio del despliegue de la imaginación radical- generando nuevas instituciones susceptibles de ser transformadas o cambiadas por otras cuando así lo decidamos colectivamente. Es decir, que la autonomía como proyecto apunta a ir caminando más allá del Estado $y$ el capital. Es en este sentido que Tischler y Navarro analizan las acciones de los pueblos en la defensa de sus recursos y de su territorio, que es en sí misma la defensa de una forma de vivir, de una visión del mundo y de una cultura que sitúa precisamente en el territorio el centro de la organización de su propia existencia como comunidades y pueblos.

¿Cómo entender lo que supone ir más allá del Estado y el capital si no entendemos que todo acto de dominio, de clausura, de reproducción, de aparente sobredeterminación, supone al mismo tiempo un acto de resistencia, de apertura, de creación y de ruptura? Aquí está el germen, ¿cómo potenciarlo? ¿Cuál es el desafío? Resistir nos exige el despliegue de nuestras posibilidades creativas. Aquí está la potencialidad. Si no somos conscientes de ella ¿cómo lograrlo?, porque, además, son precisamente el Estado y el capital las relaciones sociales fundamentales que se encargan de la fetichización que nos oculta nuestra propia fuerza: creamos lo que existe, podemos dejar de hacerlo creando otra cosa (Holloway, 2002).

Somos sujetos constructores de realidad. Nuestro hacer, pensar, ser y sentir cotidianos se dirigen, en la mayoría de los casos, a reproducir el orden existente: seguimos normas, leyes, reglamentos, costumbres, patrones culturales y otras muchas formas de relaciones sociales que no son reflexionadas por nosotros, ni las hacemos conscientes y mucho menos las cuestionamos, simplemente las obedecemos, las validamos, las repetimos, las reproducimos. Hay razones para que sea así, pero no sucede suavemente y sin contradicciones, pues son precisamente esas razones las que se ponen en tensión de manera constante por el rechazo tácito o explícito a la imposición de un interés ajeno, contrario, porque supone ir en contra de nosotros mismos, que niega nuestra voluntad, nuestro deseo, nuestra capacidad de hacer lo que en realidad queremos, porque cercena las posibilidades de despliegue pleno de nuestra humanidad. Esto es lo que habremos de hacer y seguir haciendo consciente. Lo que nos determina es nuestra propia creación, lo es el sometimiento, la dominación, la subordinación, la enajenación, la fetichización, etc., porque somos constructores cotidianos de nuestro propio proceso de humillación al negar nuestras posibilidades de vida digna, de vida autodeterminada, de vida autónoma.

Me parece que una primera línea de análisis a este respecto podría desarrollarse a partir de la siguiente pregunta: ¿cuáles son los desafíos que enfrentamos para abrir y ampliar de manera continuada esta reflexión en todos los espacios y prácticas de la vida social? Relacionada con ésta, surge otra pregunta y otras posibilidades para el análisis: ¿tenemos el deseo de desplegar otro hacer y construir nuevas relaciones sociales, sentimos la necesidad de crear un mundo diferente? Una reflexión pertinente sobre estas cuestiones, elaborada por Holloway (2011), enfatiza que hemos llegado a un punto en el que, al parecer, no hay muchas alternativas, e incluso es cada vez más claro que son sólo dos: 1) continuamos reproduciendo el mundo éste, que frustra permanentemente las posibilidades de despliegue de nuestra subjetividad y nuestra humanidad, hasta llegar a un nivel, por cierto, cada vez más cercano, en el que ya no existan las condiciones mínimas que permitan la reproducción de la vida en el planeta, en especial de la vida humana — continuar por la vía del 
capital y el Estado, esperando que éstos resuelvan otra vez temporalmente la situación, pero a costa de profundizar las contradicciones y de acelerar la debacle ambiental, liquidando definitivamente las pocas posibilidades, recursos y hasta voluntades que todavía quedan, y que con su resistencia se están expresando a favor de un cambio radical-; o 2) comenzamos a construir, aquí y ahora mismo, nuestra alternativa, viviendo y experimentando cotidianamente el mundo otro que queremos para el futuro, como posibilidad distinta al capitalismo. Esto es posible sólo creándolo a través de prácticas, saberes, pensares, sentires que vayan más allá del Estado y el capital, que no dependan de uno ni de otro, sino que exijan el despliegue de nuestras potencialidades creativas, reflexivas, de nuestra conciencia y, a partir del reconocimiento de nuestra fetichización, fragmentación, autocontradicción, etc., las utilicemos construyéndole una nueva oportunidad a la vida.

Ir más allá del Estado y el capital no garantiza de antemano que se superen todas las contradicciones y se resuelvan todos los problemas, pero las experiencias que se están construyendo en esa dirección por todo el mundo, que tenemos que seguir recuperando y también sobre las que tenemos que seguir pensando, expresan la voluntad creativa de individuos y colectivos grandes y pequeños que no quieren más de lo mismo: dependencia, frustración, rabia, indignación, ignorancia, despojo, desprecio, explotación, destrucción, muerte. Parece innegable que una de las formas de iniciar el camino que nos permita ir más allá del capital y el Estado ha de iniciar con el reconocimiento del grado de sumisión que hemos aceptado bajo las formas colonizadas del ejercicio de nuestro propio hacer, ser, saber, pensar, sentir, etc., con la aceptación tácita de que el único camino posible es el del capitalismo, precisamente una forma de vida que ha destruido toda posibilidad de vida. Es fundamental que desde ahí nos levantemos para ejercer en la práctica nuestra propia capacidad de autodeterminación, para encontrar y construir nuestras formas de vida a partir de nuestras necesidades y deseos. Considero que es indispensable acercarnos a las experiencias de quienes desde hace años y desde siempre luchan, resisten y construyen otras maneras distintas de estar en el mundo.

En la ruta para ir más allá del capital y el Estado, me parece imprescindible seguir reflexionando sobre las prácticas que, todos los días, en todas partes del mundo, y de manera más abierta y evidente o de forma más discreta, pequeña e incluso imperceptible, expresan de diversas maneras, y cada vez más consistentemente, el potencial creativo que busca propuestas propias y originales en muchísimos sentidos - al respecto, James Scott (2009) señala que al menos cien millones de personas viven al margen del capital y el Estado en una región que comparten varios países del Sudeste Asiático-, o en otros momentos lo hace retomando, desfetichizando y resignificando formas de hacer existentes que abren nuevas y múltiples posibilidades de realización al plantearse precisamente al margen del capital y el Estado - cooperativas, fábricas recuperadas, formas de producción para el autoconsumo, redes de comercialización a través del trueque, etcétera-.

Desde mi punto de vista, para ir más allá del capital y el Estado es necesario, quizás como nunca antes, defender la vida, con fuerza y con amor. Insisto en que es vital recuperar los espacios del hacer, del sentir y del pensar, la conciencia de nuestras múltiples capacidades, para construir procesos de autodeterminación continuada, esto es, en todos los espacios de la vida social, individual y colectiva. Hay que imaginar lo inexistente, lo inédito, poner en práctica otras formas de relacionarnos con el mundo y revitalizar aquellas que, si no fueron eliminadas, han estado subordinadas a las maneras imperantes de la modernidad capitalista, que ha impuesto, jerarquizado, inferiorizado, discriminado, aniquilado, despojado, anulado, asesinado... Pero ¿nada es rescatable? Creo que sólo la experiencia, la cual de muchos moods nos marca el camino para superarla, para tratar de ir mucho más allá. Hay que desplegar nuestra capacidad creativa, situarnos históricamente en el momento y, desde ahí, construir un mundo 
nuevo. $\mathrm{Al}$ respecto nos sirven, para terminar, las palabras de John Holloway (2011): "Vivir ahora el mundo que todavía no existe es la única forma de crear ese mundo [...] construyendo el mundo que creamos viviéndolo".

\section{Bibliografía}

Bautista, Rafael, 2011, “Bolivia: ¿qué significa mandar obedeciendo?", en Revista Electrónica Rebelión, 15 de marzo, en línea: <www.rebelion.org/noticia.php?id=121304>.

Hinkelammert, Franz, 1991, ¿Capitalismo sin alternativas? Sobre la sociedad que sostiene que no hay alternativa para ella", en <www.pensamientocritico.info/ articulos/articulos-de-franz-hinkelammert.html>, consultada el 20 de marzo de 2011.
Holloway, John, 2011, "Que se vayan todos (QSvT), 10 años”, en Herramienta, núm. 46.

-, 2002, Cambiar el mundo sin tomar el poder. El significado de la revolución hoy, Benemérita Universidad Autónoma de Puebla, Herramienta, México.

Khiari, Sadri, 2011, "La fuerza de la desobediencia”, en línea: <estocolmo.se/noticias/?id=434, consultada el 15 de febrero de 2011.

Scott, James, 2009, The Art of Not Being Governed, en línea: <www.amazon.com/Art-Not-Being-GovernedAnarchist/dp/0300152280\#reader_0300152280>.

Subcomandante insurgente Marcos, Comité Clandestino Revolucionario Indígena (CCRI), Comandancia General del Ejército Zapatista de Liberación Nacional (CGEZLN), 2005, Sexta Declaración de la Selva Lacandona, Chiapas.

Zibechi, Raúl, 2007, Autonomías y emancipaciones. América Latina en movimiento, Universidad Nacional Mayor de San Marcos, Programa Democracia y Transformación Global, Perú. 